\title{
Redistribution of chlorides in concrete specimens occurring during storage
}

\author{
Elisabeth Helsing (1)
}

Received: 11 September 2020/Accepted: 4 April 2021/Published online: 26 April 2021

(C) The Author(s) 2021

\begin{abstract}
It has been observed that storage of specimens with chloride gradients before determining the chloride profile can lead to changes in the shape of the chloride profile. An experimental study to quantify the influence of the duration of the storage period and the storage temperature has been carried out. It comprised three storage periods (7, 28 and 91 days) and two storage temperatures $\left(+5{ }^{\circ} \mathrm{C}\right.$ and $\left.+20^{\circ} \mathrm{C}\right)$. The specimens had previously been immersed in a $15 \% \mathrm{NaCl}$ solution for 56 days and were sealed in plastics during storage. The results show that a temperature of $+5{ }^{\circ} \mathrm{C}$ diminishes the rate of redistribution considerably, compared to a storage carried out at $+20^{\circ} \mathrm{C}$, and the longer the storage period is, the more redistribution will take place. It is also shown that it is of importance to assure that the sealing of the specimens during storage is capable of maintaining the relative humidity at the surface, so that local redistribution of chlorides close to the surface will not take place.
\end{abstract}

Keywords Concrete $\cdot$ Chloride ingress $\cdot$ Chloride profile $\cdot$ Redistribution $\cdot$ Chloride content $\cdot$ Chloride concentration

E. Helsing ( $\square)$

Research Institutes of Sweden, Infrastructure and Concrete Technology, Borås, Sweden

e-mail: elisabeth.helsing@ri.se

\section{Background and purpose}

In the first phase of a project which was primarily aimed at developing a method to determine the protection against chloride ingress of hydrophobic impregnations [1], it was found that the shape of the measured chloride profile in the specimens differed significantly. This occurred even if the concrete composition, the conditioning of the specimens before exposure to chlorides and the chloride exposure were carried out in the same way, and the tests were carried out at the same laboratory. Chloride profiles close to the exposed surface of $75 \mathrm{~mm}$ thick concrete specimens from three test series of concrete with a water-tocement ratio 0.45 , that had been immersed in $15 \%$ $\mathrm{NaCl}$ solution for 56 days is shown in Fig. 1 .

The materials and the handling of the specimens up to the point when they were taken out from the chloride solution were identical for the two series. When taken from the chloride solution all specimens in Series 1 had been wiped off and tightly wrapped in plastics, and then they were kept at constant temperature $\left(+20 \pm 2{ }^{\circ} \mathrm{C}\right)$ during the storage. One parameter that was not well controlled nor documented in Series 1 was the duration of the time period starting when the specimens were taken up from the chloride solution and ending when the specimens were drilled in steps to collect powder samples for the chloride analysis. However, all specimens from Series 1 were 


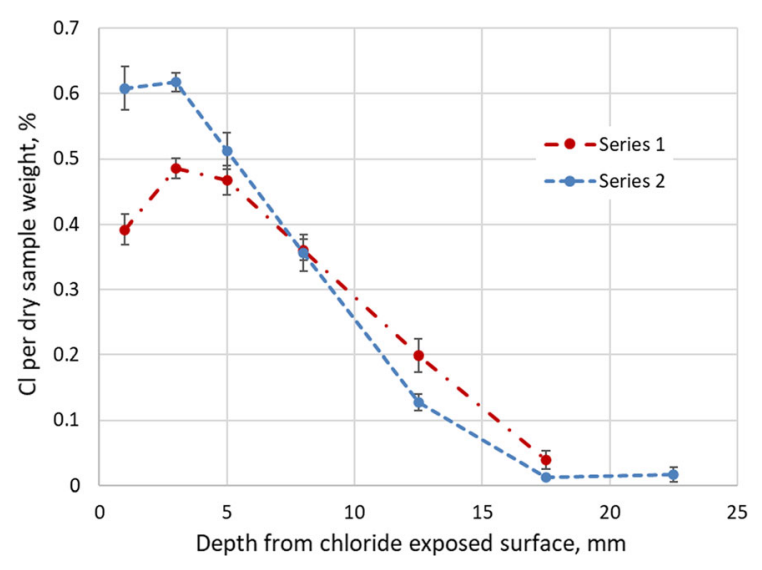

Fig. 1 Chloride profiles in concrete specimens after exposure to $15 \% \mathrm{NaCl}$-solution for 56 days in two test series with the same materials and handling up to the point when the specimens were withdrawn from the solution. Average value and standard deviation of three specimens for Series 1 and of five specimens for Series 2. Data from [1]

drilled around one month after withdrawal from the chloride solution.

In Series 2 the storage temperature was decreased to $+5{ }^{\circ} \mathrm{C}$ and the storage time was limited to maximum 7 days. This resulted in a chloride profile different from the one obtained in Series 1. This is shown in Fig. 1.

Due to these observations, a special study on the influence of the duration of the storage and the storage temperature on the chloride profiles was initiated. It was carried out on concrete specimens that previously had been immersed in $15 \% \mathrm{NaCl}$ solution for 56 days and were tightly wrapped in plastics.

\section{Materials and methods}

\subsection{Concrete and concrete specimens}

$100 \times 100 \mathrm{~mm}$ cubes were cast of concrete type MC (0.45) according to EN 1766 [2], which has as waterto-cement ratio 0.45 and a cement content of $395 \mathrm{~kg}$ / $\mathrm{m}^{3}$ concrete. Natural aggregates were used in the concrete and the coarse aggregate was crushed granite type stones with a maximum particle size of $10 \mathrm{~mm}$. A Portland cement CEM I 42.5 SR3 N according to EN 197-1 [3] was used. The cubes were demoulded after one day and then cured in water at $+20 \pm 2{ }^{\circ} \mathrm{C}$ until the age of 28 days.
The cubes were then sawed in halves and left to dry with the sawn surface facing down on a plastic sheet at $+20 \pm 2{ }^{\circ} \mathrm{C}$ and $65 \pm 5 \%$ relative humidity (RH) for 2-4 h. Thereafter, all surfaces except the sawn surface were coated with epoxy resin, which was left to harden overnight. 11 specimens (half cubes) were used for this study. The specimens were then preconditioned in $+20 \pm 2{ }^{\circ} \mathrm{C}$ and $65 \pm 5 \% \mathrm{RH}$ for 35 days with the sawn face upwards, before the start of the exposure to the salt solution.

\subsection{Chloride exposure and treatment at withdrawal}

The exposure to the salt solution was executed by totally immersing all specimens in a $15 \% \mathrm{NaCl}-$ solution in a container for 56 days at a temperature of $+20 \pm 2{ }^{\circ} \mathrm{C}$. The chloride solution was prepared by mixing $150 \pm 1 \mathrm{~g}$ of $\mathrm{NaCl}$ with water. The $\mathrm{NaCl}$ concentration was checked before and after 14 and 28 days of exposure, and if necessary adjusted. The solution in the container was stirred at least once a week during the exposure.

When the specimens were withdrawn from the chloride solution, they were carefully wiped with a squeezed cloth which had previously been moistened in the chloride solution. The specimens were then tightly sealed in plastics.

For more details about the procedures in 2.1 and 2.2 see the treatment of reference specimens in NT Build 515 [4].

\subsection{Storage of the chloride exposed specimens}

For the further treatment of the sealed specimens five different storage conditions were used:

Reference: Stored in $+5{ }^{\circ} \mathrm{C}$ and drilled for powder samples within one week from withdrawal from the salt solution. This is the treatment used in [4]. (3 specimens).

$28-5{ }^{\circ} \mathrm{C}$ : Stored in $+5{ }^{\circ} \mathrm{C}$ for 28 days and then drilled (2 specimens).

91-5 ${ }^{\circ} \mathrm{C}$ : Stored in $+5{ }^{\circ} \mathrm{C}$ for 91 days and then drilled (2 specimens).

28-20 ${ }^{\circ} \mathrm{C}$ : Stored in $+20{ }^{\circ} \mathrm{C}$ for 28 days and then drilled ( 2 specimens).

91-20 ${ }^{\circ} \mathrm{C}$ Stored in $+20{ }^{\circ} \mathrm{C}$ for 91 days and then drilled ( 2 specimens). 
2.4 Drilling for powder samples for chloride analysis

The drilling was carried out in six increments, $0-3$, $3-6,6-10,10-15,15-20$ and $20-25 \mathrm{~mm}$ from the exposed surface. All specimens exposed to the same storage condition were drilled at the same day. Immediately after drilling the powder was dried in $+105 \pm 5{ }^{\circ} \mathrm{C}$, and it was then protected from $\mathrm{CO}_{2}$ and moisture in a sealed glass vessel until the chloride analysis was carried out.

\subsection{Chloride analysis}

The content of total acid soluble chloride was analysed on $1.5 \mathrm{~g}$ powder samples with a potentiometric method using $0.1 \mathrm{M}$ silver nitrate solution. See method B in EN 14,629 [5] or AASHTO-T260 [6].

\subsection{Estimation of level of relative humidity in concrete samples}

A computer program called TorkaS [7] which is available on-line was used for estimation of the relative humidity in the concrete samples. This is a program mainly intended for calculating necessary drying periods for concrete and avoid moisture problems in buildings. The program is based on established theories concerning moisture transport and moisture fixation in concrete and experimental tests [8]. The model is presented in [9]. The input parameters used in this project are water-to-cement ratio of the concrete, the specimen geometry, the temperature and the moisture conditions at the surface of the concrete (with variations) during the period from casting to the point in time chosen, including possible presence of free water on the surface. The output is the relative humidity at different levels from the surface at the end of the chosen period. One drawback with the version of the program used in this study is that it is based on the use of a CEM II/A-LL 42.5 R, a Portland limestone cement with around $16 \%$ limestone.

\subsection{Calculation of chloride redistribution during storage}

The chloride concentration profile (in $\mathrm{g} \mathrm{Cl}$ per $\mathrm{g}$ pore water) is divided into $2 \mathrm{~mm}$ layers parallel to the surface that have been exposed to chloride solution.
The average $\mathrm{Cl}$ concentration in each layer is determined, see Fig. 2.

The first step of the change in chloride concentration of each layer is determined as $\Delta C l_{\mathrm{i}}=\left(C l_{\mathrm{i}-1}-C l_{\mathrm{i}}\right)$ - 0.5- $\left(C l_{\mathrm{i}}-C l_{\mathrm{i}+1}\right) \cdot 0.5$

For the layer at the surface $C l_{\mathrm{i}-1}$ is put equal to $C l_{\mathrm{i}}$.

This gives a new chloride concentration profile, which is the basis for calculating the changes in the next step in the same way. This iteration has been continued until the changes from the initial chloride concentration curve is in line with the magnitude of changes recorded in the experimental results.

\section{Results and discussions}

\subsection{Experimental chloride profiles}

The determined chloride profiles for the 5 different storage conditions are given in Figs. 3 and 4. Each profile is the average of the profile from the 2 or 3 specimens used in the study. The maximum and minimum values at each step are also indicated.

As can be seen in Figs. 3 and 4 there are substantial differences between the chloride profiles obtained after different storage conditions and length of storage periods. The major observations are:

- Prolonged storing causes the chloride profile to level out, i.e. where the chloride content initially is high it decreases and where it initially is low it increases.

- The changes are larger when the storage is carried out at $+20{ }^{\circ} \mathrm{C}$ than at $+5{ }^{\circ} \mathrm{C}$.

- Close to the surface there is a local large decrease in chloride content after both 28 and 91 days of storage. This occurs even where the rest of the chloride profile does not show signs of significant changes.

In order to categorize and explain the changes imposed on the chloride profiles occurring during handling and storage, the moisture and chloride profiles at the start of the storage must be known. It is also of value to know how these profiles have been created. Therefore, the principles of the penetration of chlorides into a previously dried, submerged specimen will be looked upon as a start. What may happen to the profile during the short time when the specimens are taken from the chloride bath and before they are 


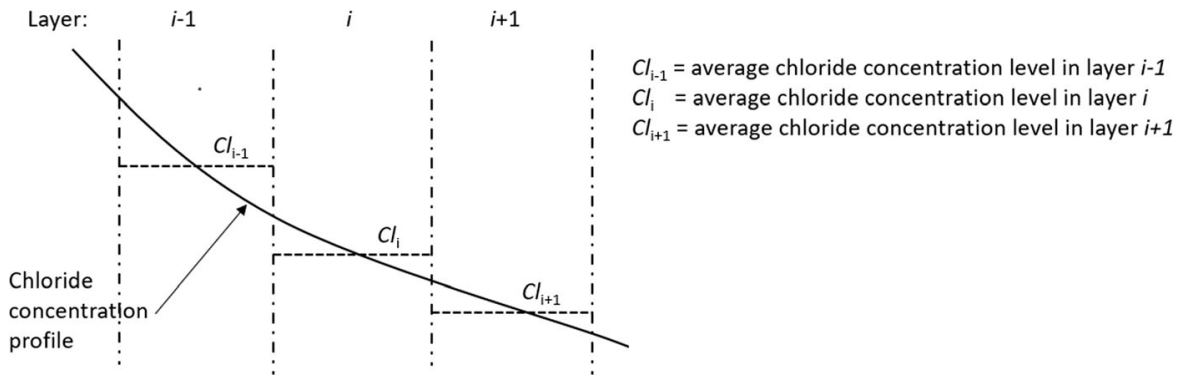

Fig. 2 Principles for layers and chloride concentrations for calculation of chloride transport

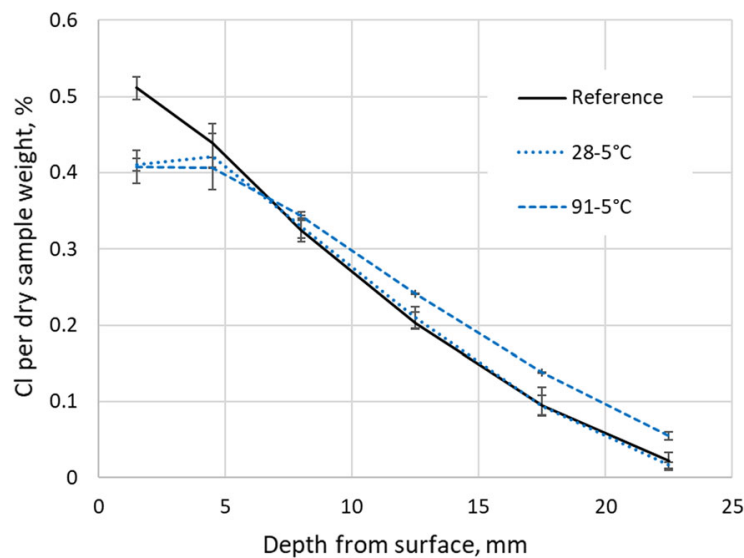

Fig. 3 Chloride profiles as $\mathrm{Cl}$ per dry sample weight in \% of the specimens stored at $+5{ }^{\circ} \mathrm{C}$ and the reference. The average is the line, and maximum and minimum values at each step are indicated

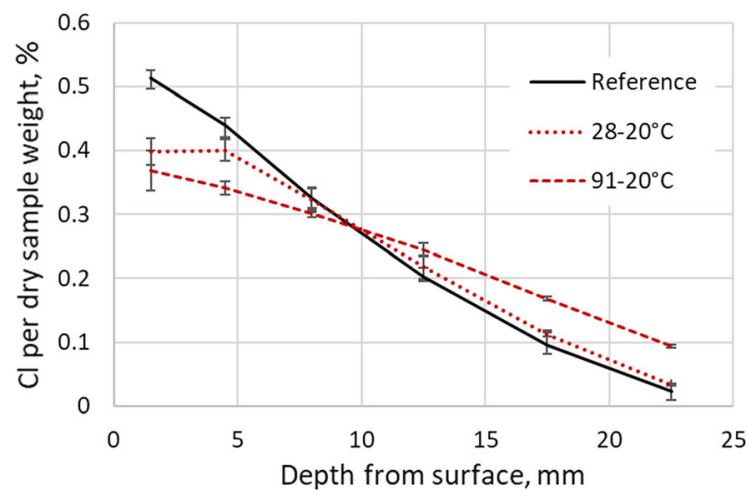

Fig. 4 Chloride profiles as $\mathrm{Cl}$ per dry sample weight in \% of the specimens stored at $+20{ }^{\circ} \mathrm{C}$ and the reference. The average is the line, and maximum and minimum values at each step are indicated

properly sealed will also be discussed. Then the influence of temperature and storage time will be treated, in conjunction with the influence of a potentially deficient sealing of the specimens, i.e. leaching of moisture through the sealing membrane during storage.

\subsection{Penetration of chlorides into mature concrete specimens totally immersed in chloride solution}

When a concrete specimen surface is exposed to a chloride solution, the chlorides penetrate the concrete by diffusion if the capillary pore system is water saturated at the start of the exposure. If the concrete has dried partially or totally beforehand, the chloride solution first saturates the pore system by capillary suction and when the pore system is saturated or an obstacle for the capillary suction occurs, the further ingress will take place through diffusion. I.e. the maximum amount of chlorides penetrating the pore system should be related to the amount of pore space available in the concrete. In a concrete exposed to a chloride solution at one surface for a long time, the maximum concentration of chlorides in the pore solution should be registered in the surface layer and it should after a certain time reach an equilibrium, which is equal to the chloride concentration in the surrounding chloride solution. In [1] it was shown that the maximum chloride content obtained in the outermost $3 \mathrm{~mm}$ of the exposed surface after 56 days exposure with the same materials and under the same conditions as in this study, was equal to that the gel and capillary pores in the concrete were filled with a chloride solution with the same chloride concentration as the bath $(15 \% \mathrm{NaCl})$. Expressed as $\mathrm{Cl}$ per dry sample weight, this corresponds to about $0.565 \%$ if the degree of hydration of the cement is 0.7 .

Although the amount of larger capillary pores and the connectivity of the pore system influences the 
transport rate, capillary suction is always a faster process than diffusion. The amount of chloride solution that enters by capillary suction in the beginning of the exposure period depends, among other things, on the percentage of the pore volume that is empty at the start. The moisture profile which reflects the degree of pore filling, depends on the concrete composition, the ambient RH-level during the period that precedes the period of exposure to the solution and the duration of this period.

However, undisturbed capillary suction into a specimen can only occur if the air in the empty pores can move through the porous system to a free surface. If a partially dried specimen is put into a basin with water so that water penetrates the specimen from all sides, the air inside the specimen will be trapped, even in a pore system with a high connectivity. When equilibrium between the capillary forces pushing inwards and the compressed air pushing outwards is achieved, the further ingress of water will be blocked [10]. The only way by which air can be transported to the surface is then by dissolution into the pore liquid, which is a very lengthy process. Thus, the moisture level in the interior of a specimen will for a long time, even if the specimen is submerged, remain at the level obtained through self-desiccation as the cement hydrates. Based on measurements on mortars with the same cement [11], the RH level anticipated in these specimens after 90 days of self-desiccation would be about $90-92 \%$.

Two RH profiles have been calculated based on the conditions used in this study with the help of TorkaS [7]. The first RH profile describes the situation occurring just before the exposure to the chloride solution. The second RH profile shows the condition

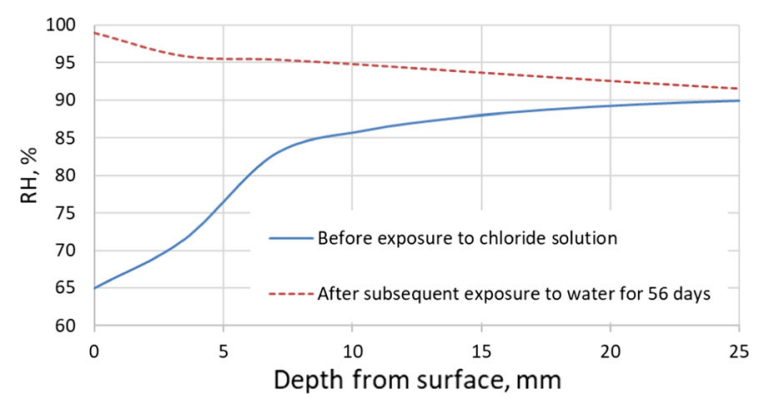

Fig. 5 RH-distribution in the specimens representing the situation before chloride exposure and after subsequent 56 days of exposure to water calculated with TorkaS [7] after subsequent exposure to water at the surface for 56 days. These are shown in Fig. 5.

The output of TorkaS is the RH profile. With the help of desorption isotherms in [12] the $\mathrm{RH}$ profiles in Fig. 4 are converted to degree of saturation profiles (filled pore volume/total gel and capillary pore volume) in the specimens, which are given in Fig. 5. The total pore volume is calculated based on traditional equations presented by Powers and Brownyard [13] and an assumed degree of hydration equal to 0.7 . However, TorkaS is based on moisture characteristics for another cement type than the one used in this study, a CEM II/A-LL according to EN197-1 [3], i.e. a Portland-limestone cement. Although it has been shown that the moisture sorption characteristics of this cement are not extremely different from those of the used CEM I [11], the curves in Figs. 5 and 6 should only be interpreted as an indication of what the moisture profiles may have looked like in the specimens in this study.

The degree of saturation in the specimen in this study with RH 90-92\% caused by self-desiccation will, based on the desorption isotherms in [12], be around 0.8 .

In Fig. 6 also a third line, which represents the difference between the two other profiles, is drawn. The total area under this line represents the amount of moisture that need to penetrate the specimen from an external source. If the only external external source available is a $15 \% \mathrm{NaCl}$ solution, this must also represent the volume of chloride solution that need to penetrate the specimen to achieve the moisture profile.

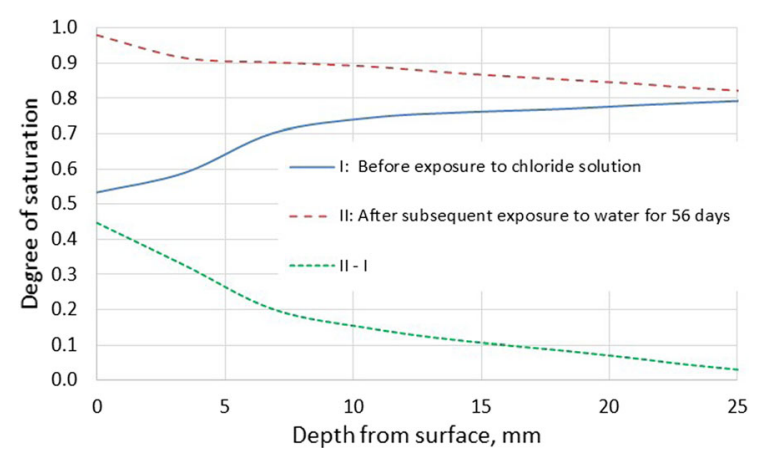

Fig. 6 Approximative moisture profiles as degree of saturation before the exposure to the salt solution and after subsequent 56 days of exposure to water. The difference between these two is also given 
However, when the specimens are submerged in chloride solution instead of water, capillary suction of the saline solution into the specimens will only fill the empty pore space completely in a layer close to the surface. Although there are empty pore spaces also in the inner parts, these spaces will not be reached by capillary transported chloride solution, since they are surrounded by water filled pores and does not form an interconnected network of empty pores.

Thus, the penetration of chlorides into the specimens is a process that consists of capillary transport of the chloride solution, diffusion of chloride solution (both moisture and chloride ions) from the surrounding liquid into the specimen and diffusion of chloride ions from the surrounding solution through the pore liquid.

In the pore space filled with liquid the chlorides will be transported into the specimens through diffusion in the liquid phase, driven by the difference in chloride concentration. The degree of pore filling (by water) in the inner parts will limit the maximum amount of chlorides that can be transported there by diffusion. If the pore liquid in the interior consisted of the $15 \%$ $\mathrm{NaCl}$ solution the maximum chloride level in the interior will be about $0.8 \times 0.565=0.452 \% \mathrm{Cl}$ per dry sample weight $(0.8$ is the degree of saturation after self-desiccation and 0.565 is the chloride content in a specimen where the pore system is completely filled with $15 \% \mathrm{NaCl}$ solution).

\subsection{Changes of the chloride profile that may occur when the specimens are taken \\ from the chloride bath and until they are sealed}

The chloride profile existing in the specimens just before it is taken from the chloride bath is governed by diffusion and capillary suction as discussed above. It will have a smooth shape, continuously decreasing with the depth, resembling the chloride profile of the reference in Figs. 3 and 4.

The handling of the specimen when taken from the bath and until it becomes sealed, may influence the shape of the chloride concentration profile or the chloride profile, if it is not carried out with great care.

If the period between uptake from the chloride solution and sealing is not as short as possible and the specimen becomes exposed to lower RHs during this period, local drying of the surface will occur, which will lead to a slightly different RH profile. This moisture decrease will be in the form of evaporation of only water, leaving the salt behind in the pores. Consequently, even though the chloride content per dry sample weight will not change, the chloride concentration in the pore liquid will be increased in the layer touched by the drying. This influence is schematically shown in Fig. 7. In this figure two examples of moderate drying at the surface (to $92 \%$ and $85 \% \mathrm{RH}$ ), which are relevant for the conditions in this study, are shown. There is also one example in this figure which shows the effect of surface drying on the chloride concentration if the RH drops to around $60 \%$ at the surface, which may well be the case if specimens are left for a certain period in laboratory atmosphere.

Besides surface drying during this period, the wiping off of excess solution from the specimen surface may influence the determined chloride profile. If this is carried out with a dry absorbent tissue, the pore liquid in the largest capillary pores in the surface layer may be sucked out. In this case also the chlorides will be included in the removed liquid. This will not change the chloride concentration in the pore liquid but may change the degree of pore filling, resulting in a slight dip in the chloride profile (in weight per sample) in the outermost part of the surface layer.

\subsection{Redistribution of chlorides during sealed storage of specimens}

What does then happen to the chloride profile during the sealed storage of the specimens?

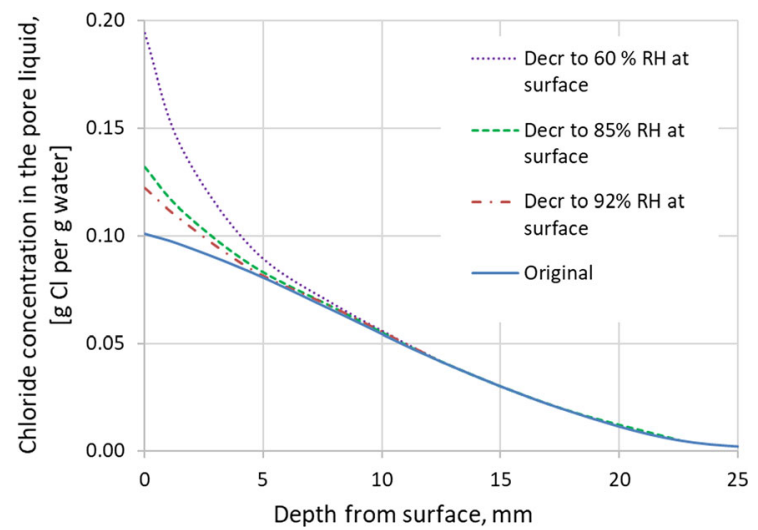

Fig. 7 Schematic influence of decreasing RH in the surface layer on the chloride concentration in the pore liquid, in a specimen that has previously been submerged in $15 \% \mathrm{NaCl}-$ solution 
If the surface of the specimens is well covered so that evaporation is made impossible and the chloride profile at the start of the storage is very close to what it is just before leaving the chloride bath, there will exist a chloride concentration gradient in the pore liquid of the specimens, high at the surface-low in inner parts. This concentration gradient will serve as driving force for diffusion of chlorides towards the inner parts.

But at the start of the storage period, there is also a moisture profile in the specimen (see Figs. 5 and 6). When the specimen is sealed the moisture will strive to level out by diffusion of liquid from the wetter surface part to the dryer inner parts, further increasing the transport of chlorides towards the interior.

If the sealing of the specimens is deficient the chloride profile will be affected. The ambient RH and the degree of moisture saturation in the surface layer of the specimen will be lowered, and the chloride concentration in the pore liquid will be increased close to the surface in the same manner as when the $\mathrm{RH}$ is lowered before the sealing is applied, as discussed in the previous section.

All these phenomena which directly or indirectly affect the chloride concentration in the pore liquid will also affect the measured chloride profile in specimens which initially have chloride gradients when they are stored for a certain period. For specimens that have previously been submerged, variations in surface conditions will at first affect the chloride profile close to the surface, and if the decrease in RH is limited and the storage time is short the influence will be limited to the outermost few mm. If the RH decrease is large and the storage time is prolonged, the effect will also be extended inwards. In the inner parts, where the humidity and chloride conditions are only marginally affected by the surface conditions, the diffusivity of the chlorides and the difference in chloride concentration in the pore liquid govern the redistribution of chlorides.

How significant this redistribution of chlorides in concrete is, depends on the permeability of the concrete, the diffusivity of the chlorides, the concentration difference, the humidity difference, the duration of the sealed storage and the quality of the sealing. Thus, if the parameters related to the initial chloride profile (concrete type, exposure to chlorides, handling of the specimens before sealing) and the sealing conditions are kept constant the changes related to the diffusivity of chlorides and storage time can be singled out..

The temperature influences the diffusion coefficient of chlorides. For the influence of temperature on the diffusion coefficient, Wu et al. [14] proposed a factor $k_{\mathrm{T}}=\exp \left(3593\left(1 / T_{\text {ref }}-1 / T\right)\right)$, where $T_{\text {ref }}$ is the reference temperature and $T$ the alternative temperature, both in Kelvin. With $T_{\text {ref }}=292 \mathrm{~K}\left(+20{ }^{\circ} \mathrm{C}\right)$ and $T=277 \mathrm{~K}\left(+5{ }^{\circ} \mathrm{C}\right), k_{\mathrm{T}}$ becomes 0.51 . In other words, the rate of diffusion in $+20{ }^{\circ} \mathrm{C}$ is about twice as high as in $+5{ }^{\circ} \mathrm{C}$. A difference between chloride diffusion coefficients in $+20{ }^{\circ} \mathrm{C}$ and in $+5{ }^{\circ} \mathrm{C}$ of the same magnitude was also recorded in [15].

In this study the influence of chloride diffusivity can best be estimated in the interior parts of the specimens, where the influence of varying surface conditions is only marginal. In Figs. 3 and 4 the horizontal displacement (horizontal distance between the reference and the other chloride profiles) at the chloride level $0.1 \%$ of sample weight, is $5 \mathrm{~mm}$ when the specimens have been stored in $+20^{\circ} \mathrm{C}$ and $2.5 \mathrm{~mm}$ when they are stored in $+5{ }^{\circ} \mathrm{C}$ for 91 days, i.e. twice as large, which complies well with [14]. When stored for only 28 days in $+5{ }^{\circ} \mathrm{C}$ the horizontal displacement of the profile in the interior parts is hardly visible. However, there may have been small changes overruled by the measurement uncertainty. 28 days storage in $+20{ }^{\circ} \mathrm{C}$ gives a visible but small horizontal displacement of the chloride profile.

Even though the sealing of the specimens were supposed to be total, one can suspect that so was not the case when looking at the chloride profiles closer to the surface in Figs. 3 and 4. The $\mathrm{Cl}$ level is not constantly decreasing as would be the case for the conditions in this study if the sealing had been perfect. If perfectly sealed the $\mathrm{RH}$ at the surface should remain at a level corresponding to about the average level over the specimen thickness when taken from the chloride bath (approx. 95\% RH). The chloride level close to the surface seems to converge towards $0.4 \%$ per sample weight. If the chloride concentration in the pore liquid in these $3 \mathrm{~mm}$ is assumed to have gone down to the same level as in the chloride bath $(15 \%$ $\mathrm{NaCl}$ solution), this corresponds to a degree of saturation of 0.72 , which corresponds to a $\mathrm{RH}$ of about $85 \%$.

The difference in chloride concentration between $5 \mathrm{~mm}$ thick layers $(\Delta C l)$ for the reference specimens with and without surface drying to $85 \% \mathrm{RH}$ (see 
Fig. 7) are given in Table 1 . Higher $\mathrm{ACl}$ close to the dried surface leads to a more rapid redistribution of chlorides in this region.

\subsection{Calculated chloride profiles}

In order to estimate how the storage time and the temperature with and without a possible drying of the surface influence the chloride profile in specimens that have been submerged in a chloride bath, theoretical chloride profiles have been calculated with different input parameters representing the storage conditions applied in this study.

The chloride profile in $\mathrm{Cl}$ per dry sample weight of the reference specimens in the experimental part of this study were used as a base, although these are not ideal, since they were not obtained directly after withdrawal of the specimens from the chloride bath but after maximum seven days storage in $+5{ }^{\circ} \mathrm{C}$. The two estimated saturation profiles in Fig. 8 were used to calculate the profile of the chloride concentration in the pore liquid for two cases, without surface drying and with surface drying to $85 \% \mathrm{RH}$.

The saturation profile for the dried surface given in this figure, will not exist at the starting point but will develop during a certain period of storage. The drop in the outermost layer will however be quick compared to the diffusion process. Therefore, for simplicity reasons, the saturation profiles in Fig. 8 have been assumed to prevail during the whole diffusion process.

The chloride concentration profiles after consecutive calculation steps where the change in each $2 \mathrm{~mm}$ layer were calculated according to the calculation shown in Sect. 2.7 for the two cases. The calculation steps may be regarded as "time steps".

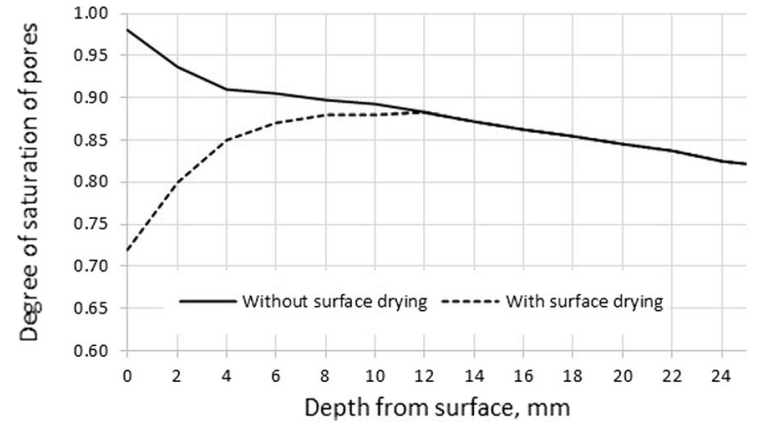

Fig. 8 Estimated degree of saturation assumed in specimens with and without surface drying used for the calculation of redistribution of chlorides

The calculated profiles for $\mathrm{Cl}$ concentration in the pore liquid and the corresponding $\mathrm{Cl}$ per dry sample weight after $0,6,12,18$ and 24 calculation steps ("time steps") for the case when no drying of the surface occurs are shown in Fig. 9a and Fig. 9b, and for the case when the surface has dried in Fig. 10a and Fig. 10b.

From Fig. 9b it becomes clear that if a high and relatively even degree of saturation is kept throughout the storage, the shape of the profile for $\mathrm{Cl}$ per dry sample weight retains a shape similar to the initial curve, but with lower levels of $\mathrm{Cl}$ at the surface and higher levels of $\mathrm{Cl}$ in the interior. The inflexion point occurs at around $10 \mathrm{~mm}$ distance from the surface, which is about half the total initial penetration depth.

If surface drying has occurred, the high $\mathrm{Cl}$ concentration close to the surface results in chloride profiles (Cl per dry sample weight) differing substantially from when drying does not occur, as can be deduced when comparing Figs. $9 \mathrm{~b}$ and 10b. This leads to increased $\mathrm{Cl}$ levels in the region about 5-10 mm depth

Table 1 Difference in chloride concentration ( $\mathrm{g} \mathrm{Cl}$ per $\mathrm{g}$ water) between $5 \mathrm{~mm}$ layers of a profile with $\mathrm{Cl}$ per dry sample weight as in the reference specimens, with and without surface drying to $85 \% \mathrm{RH}$

\begin{tabular}{|c|c|c|c|c|}
\hline \multirow[t]{2}{*}{ Layer $(i)$} & \multicolumn{2}{|c|}{ Average $\mathrm{Cl}$ concentration, $\mathrm{Cl}_{\mathrm{i}}$} & \multicolumn{2}{|l|}{$\Delta C l=C l_{i}-C l_{i+1}$} \\
\hline & No surface drying & $85 \% \mathrm{RH}$ at the surface & No surface drying & $85 \% \mathrm{RH}$ at the surface \\
\hline 1: $0-5 \mathrm{~mm}$ & 0.091 & 0.107 & 0.023 & 0.039 \\
\hline 2: $5-10 \mathrm{~mm}$ & 0.068 & 0.069 & 0.026 & 0.027 \\
\hline 3: $10-15 \mathrm{~mm}$ & 0.043 & 0.043 & 0.022 & 0.022 \\
\hline 4: $15-20 \mathrm{~mm}$ & 0.021 & 0.021 & 0.014 & 0.014 \\
\hline 5: $20-25 \mathrm{~mm}$ & 0.007 & 0.007 & 0.007 & 0.007 \\
\hline $6:>25 \mathrm{~mm}$ & 0 & 0 & 0 & 0 \\
\hline
\end{tabular}



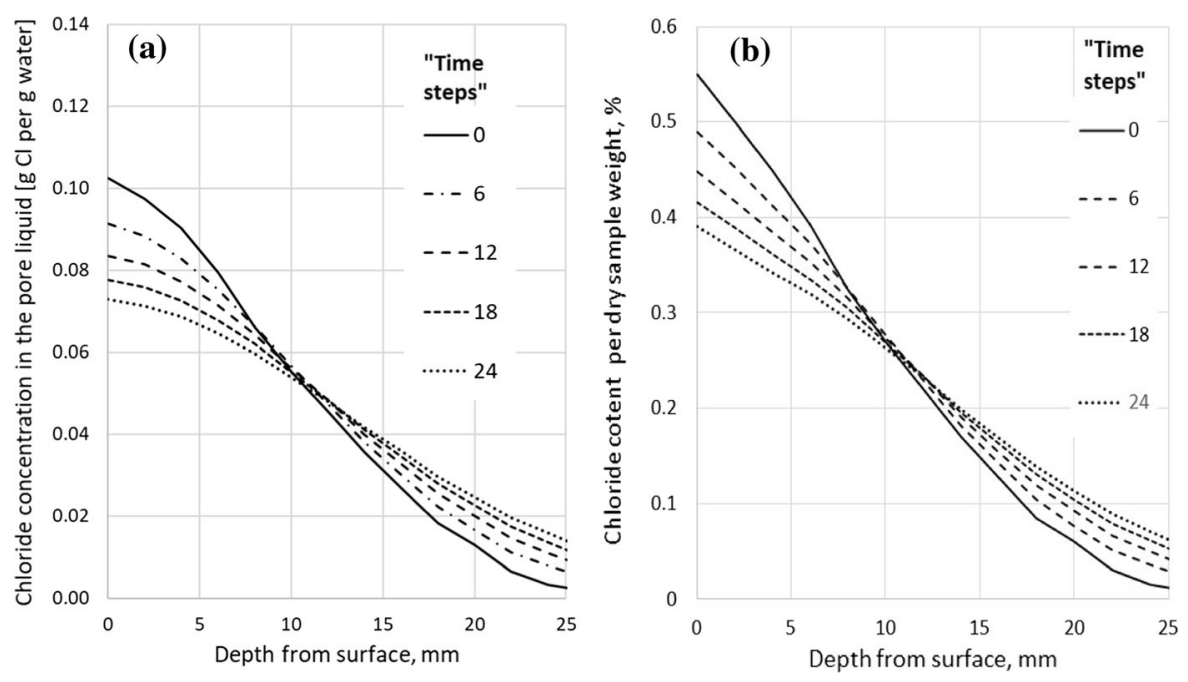

Fig. 9 Calculated $\mathrm{Cl}$ concentration in the pore liquid (a) and corresponding $\mathrm{Cl}$ per dry sample weight (b), when no surface drying occurred before or during sealed storage of specimens previously exposed to $15 \% \mathrm{NaCl}$-solution. "Time steps" are calculation steps, see text
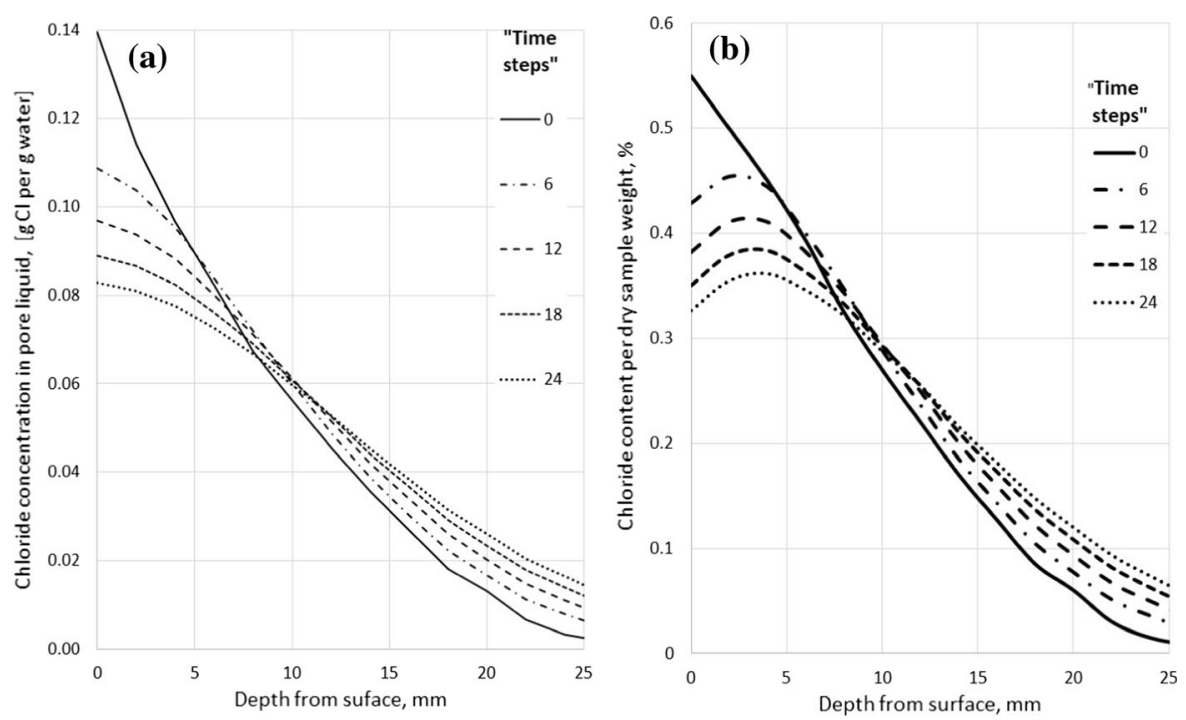

Fig. 10 Calculated $\mathrm{Cl}$ concentration in the pore liquid (a) and corresponding $\mathrm{Cl}$ per dry sample weight (b), when the surface has dried to $85 \% \mathrm{RH}$ before sealed storage of specimens previously exposed to $15 \% \mathrm{NaCl}$-solution. "Time steps" are calculation steps, see text

and lower levels at the surface. Had the surface dried to lower RH:s this "bump" at a certain distance from the surface would be even greater, as is often seen in concrete exposed to chlorides under varying RHlevels, as for instance concrete in marine splashing zones and in road environment where de-icing salts are used. See for example [16, 17].

Since the difference in chloride concentration between layers are gradually decreasing with each "time step", also the transport of chloride gradually slows down. I.e. the changes inferred from "time step" 0 to "time step" 6 are larger than the changes occurring between "time step" 18 and 24, which can be seen in the calculated $\mathrm{Cl}$ profiles.

Influence of storage period can be illustrated by comparing profiles obtained after "ss" with the same relative proportion as the durations of the storage. For example, if a chloride profile as the one obtained after 
6 "time steps" are obtained after three weeks, a profile like the one obtained after 24 "time steps" could be anticipated after twelve weeks. Evidently, the storage period influences the whole $\mathrm{Cl}$ profile substantially, both the inner parts and the parts close to the surface, irrespective if surface drying occurs during storage or not. How much the profile is changed during a certain period depends on the chloride diffusion coefficient, under otherwise identical conditions.

Differences caused by varying diffusion coefficients, due to for example differing temperature, can be indicated by comparing the profiles at different "time steps". For instance, if the diffusion coefficient is doubled, which is suggested to be the case for this type of concrete if the temperature is raised from + $5{ }^{\circ} \mathrm{C}$ to $+20{ }^{\circ} \mathrm{C}$, the number of "time steps" should also be doubled. Thus, if a chloride profile like the one achieved after 12 "time steps" is obtained at $+5{ }^{\circ} \mathrm{C} \mathrm{a}$ profile as the one obtained after 24 "time steps" could be anticipated in $+20{ }^{\circ} \mathrm{C}$.

\subsection{Comparison between experimental and calculated chloride profiles}

Comparing Figs. 3 and 4 with Figs. 9 and 10 it becomes quite clear that both storage time and temperature influence the redistribution of chlorides. Both low storage temperature and restricted storage time is necessary for ascertaining minimum redistribution of chlorides in stored specimens. But it is also very important to assure that the sealing of the specimens is effective, so that unintentional surface drying does not occur during storage. The experimental results also indicate that surface drying immediately before or during storage has occurred when the storage period was 28 days at both temperature levels, and at 91 days storage at $+5{ }^{\circ} \mathrm{C}$. However, the profile for 91 days storage at $+20{ }^{\circ} \mathrm{C}$ does not show any apparent signs of surface drying, or the diffusion is so large that such signs are camouflaged. The profile looks very much like the profile in Fig. 9 b after 24 "time steps".

3.7 Implications of the redistribution of chlorides in stored specimens on interpretation of chloride profiles and test methods

How important is then this distribution of chlorides? If the whole chloride profile is going to be used, for instance for estimating and comparing chloride diffusion coefficients of different concrete mixes, it is of importance to decrease the risk for redistribution. Otherwise the calculated diffusion coefficients may be misleading.

If, as in method NT Build 515 [4], only the total chloride content in the outermost $25 \mathrm{~mm}$ are used for calculating the efficiency of hydrophobic agents, the redistribution of chlorides does not cause a problem as long as chlorides does not penetrate beyond $25 \mathrm{~mm}$ depth during the storage. In order to minimize redistribution, this method requires a low storage temperature $\left(+5^{\circ} \mathrm{C}\right)$ and a short storage period (maximum 7 days). It also gives detailed instructions on how the specimen surface shall be wiped off. In addition to these measures, the choice of cement type may also be of interest for the results in NT Build 515 . In this study a cement with a slightly larger diffusivity than most ordinary CEM I was used, which gave an initial chloride profile reaching almost all the way to $25 \mathrm{~mm}$ depth. A cement giving an initial profile with a penetration depth of $20 \mathrm{~mm}$ as maximum is preferable, so that the risk that the profile reaches beyond $25 \mathrm{~mm}$ depth after redistribution is diminished.

\section{Conclusions}

Sealed storage of wet mature concrete specimens with chloride gradients for a certain period before determining the chloride profile, lead to changes in the shape of the chloride profile. The redistribution is mainly driven by the difference in chloride concentration in the pore liquid between different parts of the specimen. Moisture gradients also influences the $\mathrm{Cl}$ redistribution. The degree of redistribution that takes place depends on the $\mathrm{Cl}$ diffusion coefficient, which is strongly influenced by the storage temperature and the length of the storage period. The material properties, such as capillary porosity, pore size distribution and connectivity of the pore system also affects the degree of redistribution. The chloride is transported from positions with higher chloride concentration in the pore liquid to positions where the chloride concentration in the pore liquid is lower.

For specimens from the same batch of concrete, it was shown that the redistribution was about twice as fast if the storage took place in $+20^{\circ}$ as in $+5{ }^{\circ} \mathrm{C}$ due to higher diffusion coefficient. The longer the 
storage period is, the more redistribution will take place. For sealed specimens, the higher diffusion coefficient affects the chloride profile over its whole range, from the surface to beyond the initial limit for chloride penetration.

If the sealing is defective the moisture level close to the surface is lowered. This further influences the redistribution of chlorides within the specimen. If the relative humidity level close to the surface on a specimen with chloride solution in the pore system is lowered by evaporation of water, the chloride concentration in the pore liquid will increase locally, leading to a local redistribution of chlorides. This affects the shape of the chloride profile considerably, mainly in the parts close to the surface.

If the purpose of a chloride profile is to calculate chloride diffusion coefficients, it is important to minimize the redistribution during storage prior to the chloride analysis. This can be achieved by assuring an effective sealing of the specimens during storage to avoid drying of the surface, keeping the storage temperature low (around $+5^{\circ} \mathrm{C}$ ) and the storage period as short as possible (maximum 7 days is proposed).

If only the total amount of chloride that has penetrated a specimen to a certain depth is determined, redistribution is not important provided it does not transport chlorides beyond the chosen depth.

Funding Open access funding provided by RISE Research Institutes of Sweden. This study was financed by RISE, with no external funding.

\section{Declarations}

Conflict of interest The author declare that she has no conflict of interest.

Open Access This article is licensed under a Creative Commons Attribution 4.0 International License, which permits use, sharing, adaptation, distribution and reproduction in any medium or format, as long as you give appropriate credit to the original author(s) and the source, provide a link to the Creative Commons licence, and indicate if changes were made. The images or other third party material in this article are included in the article's Creative Commons licence, unless indicated otherwise in a credit line to the material. If material is not included in the article's Creative Commons licence and your intended use is not permitted by statutory regulation or exceeds the permitted use, you will need to obtain permission directly from the copyright holder. To view a copy of this licence, visit http://creativecommons.org/licenses/by/4.0/.

\section{References}

1. Helsing E, Malaga K, Silva N, Rodum E, Torkkeli M, Hejll A (2017) A Nordic method for testing hydrophobic impregnations with regard to prevention of chloride ingress, CBI report 2017:3. Research Institutes of Sweden, Borås

2. EN1766:2000 (2000) Products and systems for the protection and repair of concrete structures-test methods-reference concretes for testing. CEN, Brussels

3. EN197-1:2011 (2011) Cement-Part 1: composition, specifications and conformity criteria for common cements. CEN, Brussels

4. NT Build 515 (2015) Hydrophobic impregnations for concrete-prevention of chloride ingress-filter effect. Nordtest, Taastrup

5. EN 14629:2007 (2007) Products and systems for the protection and repair of concrete structures - test methodsdetermination of chloride content in hardened concrete. CEN, Brussels

6. AASHTO-T260 (1997) Standard method for sampling and testing for chloride content in concrete and concrete raw materials, . AASHTO, Washington

7. Torka S (2015) version 3.2, Computor program downlowded from www.fuktcentrumlth.se 2015, issued by Fuktcentrum, Lund University, Lund, Sweden

8. Johansson P (2012) Uttorkning av betong-laboratoriestudien bakom TorkaS, report TVBM-3165. Lund University, Lund, Sweden (In Swedish)

9. Arvidsson J, Hedenblad G (2007) A new model to calculate the drying of concrete. In: Proceedings from the 10th international building performance simulation association conference and exhibition, Tsinghua University, Beijing, China

10. Atlassi E (1992) Effect of moisture gradients on the compressive strength of high-performance concrete. In: Holand I (ed) High strength concrete 1993 proceedings, 3rd international conference, vol. 2, Lillehammer Norway, Norsk Betongforening, pp 646-6531

11. Atlassi E (1991) The influence of cement type on the desorption isotherm of mortar. Nordic concrete Research, volume 10, Aalborg, Denmark

12. Nilsson LO (1986) Hygroscopic moisture in concrete Drying, measurements \& related material properties, Report TVBM 1003, Lund Institute of Technology, Division of building materials, Lund, Sweden

13. Powers TC, Brownyard T (1947) Studies on the physical properties of hardened Portland cement paste, Portland Cement Association, Bulletin 22,

14. Wu H R, Zhang F J, Wang Y, Ma X W \& Jin L B (2018) Environmental factors influencing the durability of concrete structures in marine environments, Paper nr 1337. In: Sixth International Conference Conference on the Durability of Concrete Structures, 18-20 July 2018, University of Leeds, Leeds, West Yorkshire, LS2 9JT, United Kingdom

15. Yuan Q, Shi C, De Schutter G, Audenart D (2009) Effect of temperature on transport of chloride ions in concrete. In: Concrete repair, rehabilitation and retrofitting II, Alexander et al. (ed), Taylor and Francis Group, London, United Kingdom 
16. Luping T, Boubitsas D, Utgenannt P, Zareen A (2018) Chloride ingress and reinforcement corrosion - after 20 years' field exposure in a highway environment, RISE Report 2018:66, Research Institute of Sweden, Borås, Sweden

17. Boubitsas D, Tang L, Utgenannt P (2014) Chloride ingress in concrete exposed to marine environment: field data up to 20 years exposure. Research Institute of Sweden, Borås
Publisher's Note Springer Nature remains neutral with regard to jurisdictional claims in published maps and institutional affiliations. 